Pathologe 2021 - 42 (Suppl 1):S76-S80 https://doi.org/10.1007/s00292-020-00900-x Accepted: 16 December 2020

Published online: 1 March 2021

○) Springer Medizin Verlag GmbH, ein Teil von Springer Nature 2021

\section{Responsible editors}

W. Roth, Mainz

P. Boor, Aachen

\section{General information about SARS-CoV-2 and COVID-19}

Since the beginning of the COVID-19 pandemic, knowledge about course, organ involvement, and pathophysiology of severe acute respiratory syndrome coronavirus 2 (SARS-CoV-2) infection has increased rapidly. In SARS-CoV-2 infection, the virus' spike proteins bind to the angiotensin-converting enzyme receptor 2 (ACE2) on the cell surface and are cleaved by membrane proteases, allowing the virus to fuse with the host cell $[1,2]$. SARS-CoV-2 first replicates in the respiratory epithelia, and afterwards endothelial infection might occur [3]. A more detailed discussion of SARSCoV-2 and pulmonary involvement can be found in other articles in this special issue. In severe cases, the disease can have four stages:

1. Viral infection and replication,

2. Virus dissemination,

3. Severe systemic inflammation, and

4. Systemic endothelial damage, thrombosis, and multiorgan damage [4].

The German version of this article can be found under https://doi.org/10.1007/s00292020-00899-1.

This work was supported by the Federal Ministry of Health (DeRegCOVID, ZMVI1-2520COR201), the Federal Ministry of Education and Research in the framework of the Network University Medicine (DEFEAT PANDEMIcs, 01 KX2021) and the DFG (project no. 387509280, SFB1350, TP C02).

K. Amann' $\cdot$ P. Boor ${ }^{2}$ T. Wiech ${ }^{3}$ J. Singh ${ }^{4}$ E. Vonbrunn' $\cdot$ A. Knöll ${ }^{5} \cdot$ M. Hermann ${ }^{4}$. M. Büttner-Herold ${ }^{1} \cdot$ C. Daniel' $\cdot$ A. Hartmann ${ }^{6}$

' Department of Nephropathology, University Clinic Erlangen, Erlangen, Germany

${ }^{2}$ Institute of Pathology and Department of Nephrology, Section Translational Nephropathology, University Clinic of the RWTH Aachen, Aachen, Germany

${ }^{3}$ Institute of Pathology, Section Nephropathology, University Clinic Hamburg-Eppendorf, Hamburg, Germany

${ }^{4}$ Medical Clinic 3, University Clinic Erlangen, Erlangen, Germany

${ }^{5}$ Institute of Virology, University Clinic Erlangen, Erlangen, Germany

${ }^{6}$ Institute of Pathology, University Clinic Erlangen, Erlangen, Germany

\title{
COVID-19 effects on the kidney
}

In addition to the respiratory tract and the coagulation system $[5,6]$, other organs and especially the kidney can be affected [7]. Clinically, this manifests mainly in the form of acute kidney injury (AKI), the pathogenesis of which is believed to be multifactorial. Kidney cells can be directly infected via the ACE2 receptor 2 (ACE2) [8], which is expressed on proximal tubule epithelia, parietal epithelial cells, and in some cases podocytes, and can probably be inhibited by ACE2 inhibitors [9]. Secondary changes, e.g., in coagulation disorders and ischemia, are also possible. Some of these aspects will be discussed in more detail below.

\section{Renal symptoms in hospitalized COVID-19 patients}

Renal symptoms, especially AKI as the most common clinical symptom of kidney involvement, are reported in the literature with a variable extent [10]. Richardson et al. [11] found AKI in more than $20 \%$ of patients treated in a New York hospital $(n=5700)$, of whom $3.2 \%$ require renal replacement therapy. A study from Wuhan [12] reported that about $20 \%$ of COVID-19 intensive care patients with AKI became dialysis patients. In another Chinese study [13] of 701 patients, $43.9 \%$ of hospitalized COVID19 patients were reported to have proteinuria, $26.7 \%$ to have hematuria, and $13.1 \%$ to have a glomerular filtration rate (GFR) of $<60 \mathrm{ml} / \mathrm{min} / 1.73 \mathrm{~m}^{2}$. Subsequently, $5 \%$ of these patients developed AKI. COVID-19 patients who develop
AKI have a significantly worse outcome with a higher risk of death.

\section{COVID-19 renal symptomatol- ogy in chronic kidney disease and kidney transplant patients}

Pre-existing chronic kidney disease (CKD) appears to be associated with an increased risk of more severe COVID-19 infection and mortality [13, 14]. From the Austrian Dialysis and Kidney Transplant Registry, it is known that between mid-March and early April 2020 the number of COVID-positive patients in this registry increased dramatically, then remained at a high plateau and recently increased again. SARS-CoV-2 infected kidney patients showed high overall mortality: $27.9 \%$ of infected dialysis patients and $6 \%$ of kidney transplant patients died of or with COVID 19 infection according to this registry. Of the total of 18 deaths, $14(77.7 \%)$ were considered a direct result of SARSCoV-2 infection. These findings are also confirmed by the data of the EDTA registry [14, p. 1540-1548], wherein particularly the very high mortality of $44.3 \%$ due to COVID-19 in the group of kidney-transplanted patients $\geq 75$ years is emphasized. This represents a 1.28fold increase in mortality compared to a matched dialysis cohort, making renal transplant patients a particularly vulnerable population, presumably due to the underlying renal disease and multiple comorbidities. However, in addition to increased mortality, COVID-19 infec- 


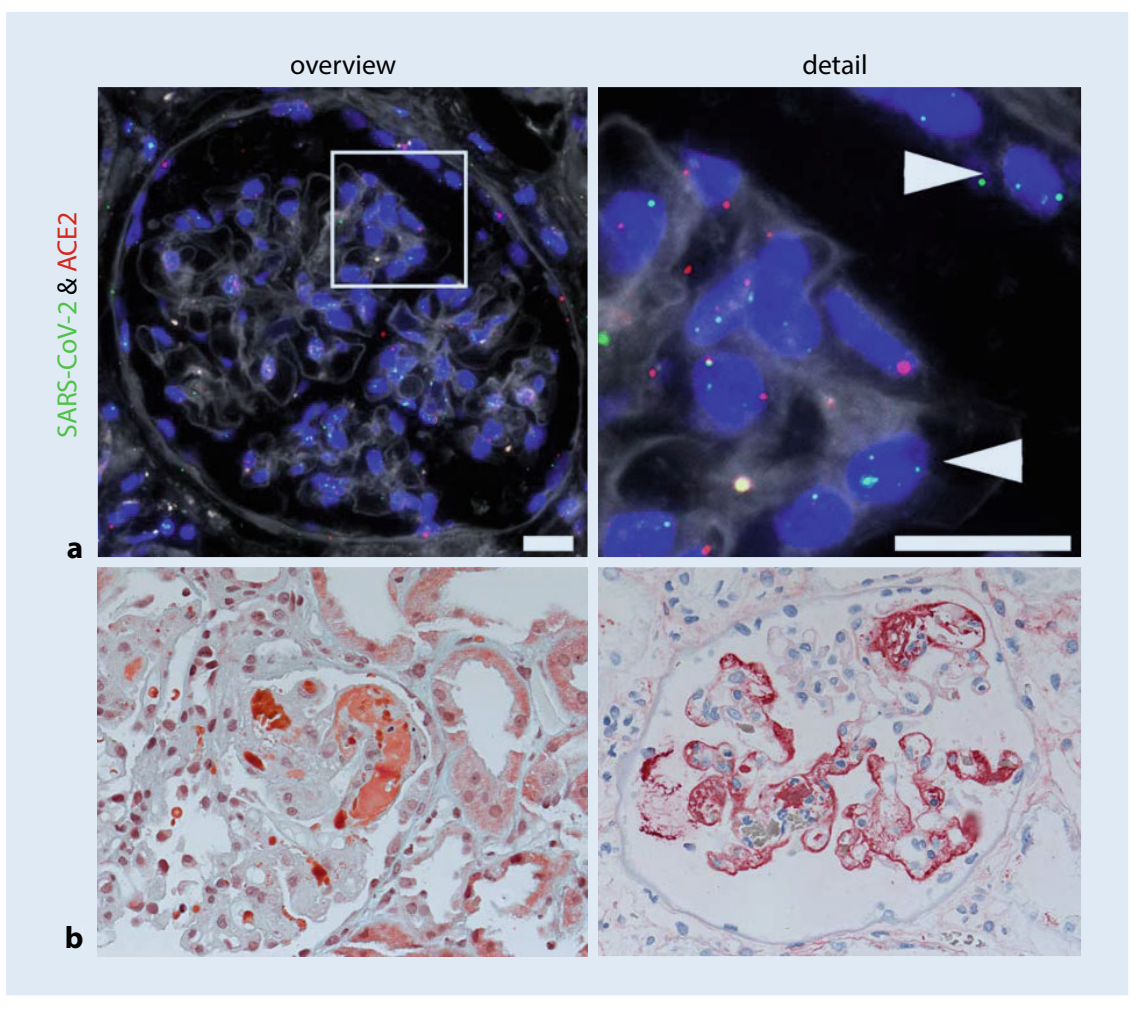

Fig. $1 \Delta$ SARS-CoV-2 virus detection in kidney and characteristic glomerular changes. a SARS-CoV-2 virus detection in the kidney. Fluorescence in situ hybridization (FISH) shows RNA expression of SARS-CoV-2 virus (green; arrows) and its receptor angiotensin-converting enzyme 2 (ACE2; red) in the glomerulus of the kidney of a COVID-19 patient. Scale bar $=20 \mu \mathrm{m}$ (from [36]). b Renal histology of a 38-year-old patient with COVID-19 and acute renal failure. Left: Masson-Goldner staining shows fresh, wall-bound fibrin thrombi (orange) in the glomerular capillaries. Right: Immunohistochemistry for fibrinogen/fibrin shows wall-adherent precipitates (red) in numerous glomerular capillaries

tion in renal transplant patients also appears to have other functional effects, as illustrated by numerous case reports that have now been published $[15,16]$.

\section{Morphological kidney changes and pathophysiology of kidney damage in COVID-19}

Specific changes or pathognomonic morphological lesions as in other viral diseases, e.g., diffuse interstitial edema and interstitial erythrocyte extravasations in the cortex-marrow junction area in hantavirus nephropathy, or characteristic nuclear virus inclusion bodies as in polyoma and cytomegalovirus infection, are not present or have not been described so far in SARS-CoV-2 infection [17]. In the studies published to date as well as our observations, acute tubule epithelial damage of varying degrees with dilated tubules, flattened or vacuolated epithelial cells, and thickened material in the tubule lumen are the dominant histological features. Su et al. [18] examined renal tissue from 26 COVID-19 patients, 9 of whom had clinical evidence of renal damage. Acute damage of the proximal tubules with increased vacuolization up to necrosis and erythrocyte aggregates in the glomerular and peritubular capillaries were the main findings in light microscopy, whereby a few cases also showed pigmented cylinders. In the autopsy study by Menter et al. [19], the kidneys of 18 deceased COVID-19 patients were analyzed and acute tubule damage with dilated clearings, flattened epithelium, and interstitial edema were also described as the most frequent findings. Three patients also showed small fibrin thrombi in the glomerular capillaries, consistent with disseminated intravascular coagulation (DIC), as also described in the context oflung involvement in COVID-19. Bleeding, inflammatory vascular changes, or interstitial nephritis were not observed in either study, but this does not exclude pathophysiological involvement of inflammatory processes such as increased cytokine or complement activation. However, these factors are difficult to demonstrate specifically in tissue.

Recently, several papers have appeared in international nephrological journals dealing with autopsy and kidney biopsy findings in SARS-CoV-2 positive patients [20-22]. Also in these studies, acute tubule epithelial damage was found, but characteristic virus particles were not seen in most studies, suggesting an indirect cause of AKI. In a recently published study, Werion and colleagues [23] examined 49 hospitalized patients and found a specific dysfunction of the proximal tubules in a subgroup, without any known previous disease. Structurally, tubule damage was found with loss of the brush border, acute tubule necrosis, intratubular debris, and reduced expression of the endocytosis receptor megalin in the brush border. Electron microscopy revealed virus-like particles in vacuoles or cisterns of the endoplasmic reticulum (ER).

Discussion on current paradigms of the pathophysiology and treatment of AKI in COVID-19 have been published by Ronco and Reis [24]. In addition to the direct viral attack of local kidney cells via the ACE2 receptor, several indirect factors play a role, which are associated with secondary kidney damage. For example, the very frequent lung involvement in COVID-19 can lead to a reduced oxygen saturation of the blood and thus to ischemic damage, especially of the very energy-dependent proximal tubules. Besides, a virus-induced activation of the complement system can be assumed, which systemically or locally in the kidney leads to inflammation and cell damage via the release of mediators such as cytokines [25]. Such complement activation could also increase damage to other organs and promote hypercoagulopathy, which can lead to arterial fibrin thrombi and disseminated intravascular coagulation (DIC), resulting in reduced renal perfusion (- Fig. 1b). Arterial thrombi in pulmonary vessels lead to increased pulmonary resistance and 
to right heart strain, which in turn promotes AKI in hypo-oxygenated blood. Furthermore, a pathophysiological role of the so-called neutrophil extracellular traps (NET) for the microcirculation disturbance in severe COVID-19 courses has also been described in the kidney [26]. COVID-19 patients show activation and degranulation of the neutrophil granulocytes in the blood and an increased formation of NETs, which in turn can completely or partially occlude blood vessels and lead to tissue damage. Recently, such changes have also been demonstrated in the kidneys of deceased COVID-19 patients [26]. Another recent paper by Schulte-Schrepping et al. [27] from the German COVID-19 OMICS Initiative (DeCOI) also points to an important pathophysiological role of dysfunctional neutrophil granulocytes or a dysregulated immune response in COVID-19 infection, which may also explain why patients with comorbidities such as diabetes mellitus and impaired immune competence have an increased mortality risk.

Furthermore, a possible association between glomerular proteinuria disease and SARS-CoV-2 infection as well as a possible association with renal high-risk APOL1 genotype is reported [28]. These and other findings are also summarized in a review article $[29,30]$.

\section{SARS-CoV-2 pathogen diagnostics on fixed kidney tissue}

SARS-CoV-2 RNA can be detected in kidney tissue and seems to be currently the most sensitive and specific virus detection method. On the one hand, the PCR-based method can be used. After isolation of RNA from the tissue (fresh or formalin-fixed and paraffin-embedded), specific RNA sequences of SARS-CoV-2 are detected in a PCR reaction similar to a smear test. This method is particularly well suited for high throughput and confirmation of infection. On the other hand, the viral RNA can be detected directly in the tissue section by in situ hybridization (ISH). For this purpose, complementary probes are used, which bind specifically to the viral RNA. This

Pathologe 2021 - 42 (Suppl 1):S76-S80 https://doi.org/10.1007/s00292-020-00900-x

(c) Springer Medizin Verlag GmbH, ein Teil von Springer Nature 2021

\section{K. Amann · P. Boor · T. Wiech · J. Singh · E. Vonbrunn · A. Knöll · M. Hermann · M. Büttner- Herold · C. Daniel · A. Hartmann \\ COVID-19 effects on the kidney}

\begin{abstract}
Apart from pulmonary disease, acute kidney injury (AKI) is one of the most frequent and most severe organ complications in severe coronavirus disease 2019 (COVID-19). The SARS-CoV-2 virus has been detected in renal tissue. Patients with chronic kidney disease (CKD) before and on dialysis and specifically renal transplant patients represent a particularly vulnerable population. The increasing number of COVID-19 infected patients with renal involvement led to an evolving interest in the analysis of its pathophysiology, morphology and modes of virus detection in the kidney. Meanwhile, there are ample data from several autopsy
\end{abstract}

and kidney biopsy studies that differ in the quantity of cases as well as in their quality. While the detection of SARS-CoV-2 RNA in the kidney leads to reproducible results, the use of electron microscopy for visualisation of the virus is difficult and currently critically discussed due to various artefacts. The exact contribution of indirect or direct effects on the kidney in COVID-19 are not yet known and are currently the focus of intensive research.

\section{Keywords}

Acute kidney injury - Coronavirus infections . Electron microscopy · Neutrophil extracellular traps (NETs) · SARS-CoV-2

\section{COVID-19-Auswirkungen auf die Niere. Englische Version}

\section{Zusammenfassung}

Bei einer schweren Coronavirus-Erkrankung2019 (COVID-19) ist neben der Lungenerkrankung selbst das akute Nierenversagen (ANV) eine der häufigsten und schwerwiegendsten Komplikationen. Das SARS-CoV-2-Virus konnte hierbei auch in der Niere nachgewiesen werden. Patienten mit chronischen Nierenerkrankungen (CKD), dialysepflichtige sowie v. a. nierentransplantierte Patienten scheinen eine besonders vulnerable Population darzustellen. Die zunehmende Anzahl SARS-CoV-2infizierter Patienten hat das Interesse an der genauen Pathophysiologie und Morphologie der Nierenschädigung sowie am direkten Virusnachweis in der Niere geweckt, der im Gegensatz zur Lunge insgesamt schwieriger zu führen ist. Hierzu liegen mittlerweile Daten aus Autopsie- und Nierenbiopsiestudien mit unterschiedlichen Patientenzahlen und von sehr unterschiedlicher Qualität vor. Während der Nachweis von SARS-CoV-2-RNA im Nierengewebe mit gut reproduzierbaren Ergebnissen erfolgt, ist insbesondere der Virusnachweis mittels Elektronenmikroskopie schwierig und wird aufgrund zahlreicher Artefakte derzeit kritisch diskutiert. Die genauen direkten oder indirekten Effekte von SARS-CoV-2 auf die Niere sind noch nicht im Detail bekannt und derzeit der Fokus intensiver Forschung.

\section{Schlüsselwörter}

Akuter Nierenschaden - Coronavirus-Infektionen - Elektronenmikroskopie - Neutrophile extrazelluläre Netze (NETs) · SARS-CoV-2 binding can be visualized using fluorescent (FISH) or chromogenic (CISH) dyes $[15,16]$. This method is somewhat more complex but offers a cell-specific analysis of the virus location. It is also possible to analyze other genes (or proteins) in parallel in the same cell, e.g., the virus receptor ACE2, using double or multiple ISH (• Fig. 1a). Using these methods it was possible to show that SARS-CoV-2 RNA is not only found in the lung but to a lesser extent also in various other organs, including the kidney. A recently published paper compared the methods of virus detection on kerosene material and showed that in situ virus detection at both the RNA and protein level is usually more difficult in the kidney than in the lung [31]. In the autopsy study by Braun et al. [32], SARS-CoV-2 RNA detection in the kidney was successful in $60 \%(38 / 63)$ of patients. This finding was associated with higher age, a higher number of comorbidities, and a shortened patient survival.

Ultrastructural examination by electron microscopy (EM) for SARS-CoV-2 virus detection should also be mentioned. 
The EM is used as a standard method in nephropathology (and cardiac pathology) for the detection or confirmation of a viral infection such as CMV or polyomavirus. Although the ultrastructural detection of SARS-CoV-2 in human tissue, and especially autopsy material, is far from trivial, EM and also more specific methods such as immunogold EM or correlative light microscopic EM (CLEM) have a possible diagnostic value [33]. Nicely illustrated studies by Roufosse et al. [34] and Hopfer et al. [35] comment on the problems of virus detection by EM and point out various artifacts that can imitate virus particles. Thus, caution is required when using electron microscopy for virus detection or interpretation of electron microscopic images and findings, as there are numerous pitfalls and structures that look very similar to virus particles. A more detailed discussion of the detection methods can also be found in another article in this special issue.

Finally, it should be mentioned that in addition to the possibly artifact-prone methods and technical aspects just mentioned, it is still necessary to critically assess the currently available findings on COVID-19 and kidney. Most of these were obtained in a very short time, published quickly, and, at least in some cases, apparently without a thorough review process. It remains opened which of this knowledge will stand up to critical examination in larger numbers of cases or with the corresponding controls.

\section{Practical conclusions}

- In the course of a severe infection with the SARS-CoV-2 virus, renal dysfunction and acute renal insufficiency often occur in patients with healthy kidneys and especially in patients with kidney disease with pre-existing chronic damage.

- Acute renal failure is histomorphologically characterized by severe diffuse acute tubule damage.

- How the acute component of kidney failure occurs has not yet been fully clarified in detail, but is presumably multifactorial etiology. Both direct viral effects via the angiotensin- converting enzyme receptor 2 (ACE2 receptor) present on numerous kidney cells and indirect effects such as impaired perfusion or cytokine and complement activation could play a role.

- In contrast to other renal involvement in systemic viral infection, SARSCoV-2 does not cause acute T-cell mediated interstitial nephritis and no specific glomerulonephritides have been reported.

\section{Corresponding address}

\section{Prof. Dr. K. Amann}

Department of Nephropathology, University Clinic Erlangen

Krankenhausstr. 8-10, 91054 Erlangen, Germany

Kerstin.Amann@uk-erlangen.de

\section{Compliance with ethical guidelines}

Conflict of interest. K. Amann, P. Boor, T. Wiech, J.Singh, E. Vonbrunn, A. Knöll, M. Hermann, M. BüttnerHerold, C. Daniel and A. Hartmann declare that they have no competing interests.

For this article no studies with human participants or animals were performed by any of the authors. All studies performed were in accordance with the ethical standards indicated in each case. The supplement containing this article is not sponsored by industry.

\section{References}

1. Zhou P et al (2020) A pneumonia outbreak associated with a new coronavirus of probable bat origin. Nature 579(7798):270-273

2. Gheblawi $M$ et al (2020) Angiotensin-converting enzyme 2: SARS-coV-2 receptor and regulator of the renin-angiotensin system: celebrating the 20th anniversary of the discovery of ACE2. Circ Res 126(10):1456-1474

3. Gupta A et al (2020) Extrapulmonary manifestations of COVID-19. Nat Med 26(7):1017-1032

4. Cordon-Cardo C et al (2020) COVID-19: staging of a new disease. Cancer Cell 38(5):594-597

5. Wichmann D et al (2020) Autopsy findings and venous thromboembolism in patients with COVID19: a prospective cohort study. Ann Intern Med 173(4):268-277

6. Zou L et al (2020) SARS-CoV-2 viral load in upper respiratory specimens of infected patients. N Engl J Med 382(12):1177-1179

7. Puelles VG et al (2020) Multiorgan and renal tropism of SARS-coV-2. N Engl J Med 383(6):590-592. https://doi.org/10.1056/ NEJMc201140

8. Gavriatopoulou M et al (2020) Organ-specific manifestations of COVID-19 infection. Clin
Exp Med. https://doi.org/10.1007/s10238-02000648-x

9. Allison SJ (2020) SARS-CoV-2 infection of kidney organoids prevented with soluble human ACE2. Nat Rev Nephrol 16(6):316. https://doi.org/10. 1038/s41581-020-0291-8

10. Rubin $S$ et al (2020) Characterization of acute kidney injury in critically ill patients with severe coronavirus disease 2019. Clin Kidney J 13(3):354-361

11. Richardson Setal (2020) Presenting characteristics, comorbidities, and outcomesamong 5700 patients hospitalized with COVID-19 in the New York City area. JAMA 323(20):2052-2059

12. Zhou F et al (2020) Clinical course and risk factors for mortality of adult inpatients with COVID-19 in Wuhan, China: a retrospective cohort study. Lancet 395(10229):1054-1062

13. Cheng $Y$ et al (2020) Kidney disease is associated with in-hospital death of patients with COVID-19. KidneyInt 97(5):829-838

14. Jager KJ et al (2020) Results from the ERAEDTA registry indicate a high mortality due to COVID-19 in dialysis patients and kidney transplant recipients across europe. Kidney Int 98(6):1540-1548. https://doi.org/10.1016/j.kint. 2020.09.006

15. Westhoff TH et al (2020) Allograft infiltration and meningoencephalitis by SARS-CoV-2 in a pancreas-kidney transplant recipient. Am J Transplant 20(11):3216-3220

16. Doevelaar AAN et al (2020) Lessons for the clinical nephrologist: recurrence of nephrotic syndrome induced by SARS-CoV-2. J Nephrol 33(6):1369-1372

17. Remmelink Met al (2020) Unspecific post-mortem findings despite multiorgan viral spread in COVID19 patients. Crit Care 24(1):495

18. Su H et al (2020) Renal histopathological analysis of 26 postmortem findings of patients with COVID19 in China. Kidney Int 98(1):219-227. https://doi. org/10.1016/j.kint.2020.04.003

19. Menter T et al (2020) Postmortem examination of COVID-19 patients reveals diffuse alveolar damage with severe capillary congestion and variegated findings in lungs and other organs suggesting vascular dysfunction. Histopathology 77(2):198-209. https://doi.org/10.1111/his.14134

20. Santoriello D et al (2020) Postmortem kidney pathology findings in patients with COVID-19. J Am Soc Nephrol 31(9):2158-2167

21. Golmai $P$ et al (2020) Histopathologic and ultrastructural findings in postmortem kidney biopsy material in 12 patients with AKI and COVID19. JAm Soc Nephrol 31 (9):1944-1947

22. Sharma P et al (2020) COVID-19-associated kidney injury: a case series of kidney biopsy findings. J Am Soc Nephrol 31(9):1948-1958

23. Werion A et al (2020) SARS-coV-2 causes a specific dysfunction of the kidney proximal tubule. Kidney Int 98(5):1296-1307

24. Ronco C, Reis T (2020) Kidney involvement in COVID-19 and rationale for extracorporeal therapies. Nat Rev Nephrol 16(6):308-310. https:// doi.org/10.1038/s41581-020-0284-7

25. Risitano AM et al (2020) Complement as a target in COVID-19? Nat Rev Immunol 20(6):343-344

26. Leppkes $M$ et al (2020) Vascular occlusion by neutrophil extracellular traps in COVID-19. EBioMedicine 58:102925

27. Schulte-Schrepping J et al (2020) Severe COVID19 is marked by a dysregulated myeloid cell compartment. Cell 182(6):1419-1440.e23 


\section{Schwerpunkt: COVID-19}

28. Shetty AA et al (2020) COVID-19-associated glomerular disease. J Am Soc Nephrol 32(1):33-40. https://doi.org/10.1681/ASN.2020060804

29. Nadim MKet al (2020) COVID-19-associated acute kidney injury: consensus report of the 25th acute disease quality initiative (ADQI) workgroup. Nat Rev Nephrol 16(12):747-764

30. Nadim MKetal (2020) Publisher correction: COVID19-associated acute kidney injury: consensus report of the 25(th) acute disease quality initiative (ADQI) workgroup. Nat Rev Nephrol 16(12):765

31. Best Rocha A et al (2020) Detection of SARS$\mathrm{CoV}$-2 in formalin-fixed paraffin-embedded tissue sections using commercially available reagents. Lab Invest 100:1485-1489

32. Braun F et al (2020) SARS-CoV-2 renal tropism associates with acute kidney injury. Lancet 396(10251):597-598

33. Farkash EA, Wilson AM, Jentzen JM (2020) Ultrastructural evidence for direct renal infection with SARS-coV-2. J Am Soc Nephrol 31(8):1683-1687

34. Roufosse $C$ et al (2020) Electron microscopic investigations in COVID-19: not all crowns are coronas. Kidney Int 98(2):505-506. https://doi. org/10.1016/j.kint.2020.05.012

35. Hopfer $\mathrm{H}$ et al (2020) Hunting coronavirus by transmission electron microscopy - a guide to SARS-CoV-2-associated ultrastructural pathology in COVID-19 tissues. Histopathology. https://doi. org/10.1111/his.14264

36. Amann K, Boor P, Wiech T (2020) COVID-19 und Nierenbefall. Nephrologe. https://doi.org/10. 1007/s11560-020-00469-9 